\title{
Bifid ribs: a comprehensive review
}

\author{
Andrea Andrea ${ }^{1}$, Gabrielle Tardieu ${ }^{2}$, Christian Fisahn ${ }^{1,3}$, Joe Iwanaga ${ }^{1}$, \\ Rod J. Oskouian ${ }^{1,3}$, R. Shane Tubbs ${ }^{1}$ \\ ${ }^{1}$ Seattle Science Foundation, Seattle, Washington, USA \\ ${ }^{2}$ Faculty of Medicine, St. George's University, Grenada, West Indies \\ ${ }^{3}$ Swedish Neuroscience Institute, Swedish Medical Center, Seattle, Washington, USA
}

\begin{abstract}
Bifid or bifurcated ribs are a rare anatomical anomaly that accounts for approximately $28 \%$ of known rib abnormalities. Bifurcation always occurs at the sternal end of the rib and its two extremities are joined to a bifid costal cartilage. The presence of bifid rib is frequently accompanied by other anomalies, although this does not necessarily imply that it cannot occur as an isolated anomaly. The clinical significance of the latter has not been established. There have not been many studies done to investigate bifid rib closely aside from individual case reports, presumably due to the condition's extremely low incidence. However the detection of bifid ribs, though mostly incidental, has been proven advantageous for an early and wellrounded diagnosis It has also revealed significant preventive benefits especially in the pediatric patient population. This review is written to provide a comprehensive summary of what is known about bifid ribs and incorporate substantial findings from clinical cases that have been reported in past literature.
\end{abstract}

Keywords: anatomy; bone; developmental; embryology; thorax; variation

Anatomy 2016;10(3):221-227 @2016 Turkish Society of Anatomy and Clinical Anatomy (TSACA)

\section{Introduction}

Anatomical abnormalities of the ribs occur in an average $2 \%$ of the population. ${ }^{[1,2]}$ Bifid rib accounts for $28 \%$ of thispercentage $^{[1]}$ (Figure 1). When multiple bifurcations occur, they are mostly unilateral, although some bilateral cases have been reported. ${ }^{[3]}$ Bifurcation is most common at the third or fourth ribs, and occurs more on the right side than the left. ${ }^{[3-5]}$ Nearly all studies have reported a higher occurrence of bifid rib in males than females, ${ }^{[4,5]}$ except for one study that was published in 2015. Song et al ${ }^{[4]}$ recognized two morphological patterns of bifid ribs: (1) Bifid rib has the appearance of a two-pronged fork with fissured, long and slender bifid space; and (2) bifid rib with a more rounded bifid space. These arecoined fork and hole types, respectively. ${ }^{[4]}$ Song et al. ${ }^{[4]}$ also proposed the distinction between the developments of the two. The fork type is likely to have developed through the dividing of the rib in the anterior portion, while the hole type formed from the upper branch growing out of the lower branch of the bifurcation. ${ }^{[4]}$ The basis of the hypotheses was not elaborated upon.
The ribs are derived from the ventral extension of the sclerotomic mesenchyme that forms the vertebral arches. ${ }^{[6]}$ The entire extension of the thoracic region known as the 'primitive costal arch' undergoes chondrification followed by subsequent ossification and form the ribs. ${ }^{[6]}$ In a bifid rib, the distal parts of the osseous rib bifurcated at a $60^{\circ}$ angle. ${ }^{[6]}$ Both the upper and lower divisions have their own costal cartilage. ${ }^{[6]}$ The costal cartilage again fuses to form the trunk that is connected to the sternum. ${ }^{[6]}$ Multiple cases reported in a study indicated that the upper intercostal space of the bifid rib was narrowed, while the lower intercostal space widened. ${ }^{[4]}$ It is presumed that the bifid intercostal space was filled with intercostal muscles. ${ }^{[3,4]}$ The distribution of nerves and blood vessels is relatively constant in all cases: Arterial and venous branches originate from the inner thoracic artery and vein ("upper costal branches") and ran towards the upper branch of the bifid ribs; while intercostal nerves ran along the lower margin of the lower branch instead of bifurcating, leaving the upper branch without an intercostal nerve..$^{[3,4,7]}$ 
Based on the aforementioned uniformity, ${ }^{[4]}$ put forward several hypotheses regarding the anatomical development of bifid ribs. The following lists the hypotheses along with the observation on which each one is grounded; (1) The upper branch is the abnormal portion of the bifurcation, judging from the fact that the distance from the lower branch is equal to the width of the lower intercostal space; (2) The lower division formed the original rib and the upper division grew out of the lower division, judging from the normal presence of intercostal muscles in the bifid intercostal space; (3) The intercostal muscle in the bifid space originated from muscles of the $3 \mathrm{rd}$ intercostal space and was separated from one another by the upper division of the bifurcation, judging from the fact that the artery supplying the bifid space branched from the upper (anterior) intercostal artery; (4) The intercostal nerve distribution, running along the lower margin of the lower division of the bifurcation but absent in the upper division, further strengthens the hypothesis that the lower branch did not grow out of the upper branch; and (5) The direction of growth of a bifid rib is dominantly lateral, rather than medial, judging from the fact that only the lateral portion of the upper division is present.

In 2006, Oostra and Maas ${ }^{[8]}$ also made a contribution in proposing the origins of bifid rib. They suggested that the anomaly had an early developmental origin, plausibly during the re-segmentation of the sclerotomes that leads to vertebral formation. Unlike other rib anomalies, bifid ribs do not generally co-occur with vertebral defects. ${ }^{[1]}$ Based on this fact, it is highly likely that the proposed defect in intersclerotomal fusion only concerned the laminar and costal sclerotome derivatives. ${ }^{[8]}$ In addition, Oostra and Maas $^{[8]}$ noted a striking resemblance between the combination of anomalies in their case and a mice mutant known as the open brain (opb). The phenotypical features of this mutation include severe malformations of the vertebral column, mostly evident in the upper thoracic region. ${ }^{[9]}$ As expected, bifid rib is one of these malformations. The homozygously lethal mutation arouse from a homozygous stop codon mutation in the Rab23 gene. This had led Oostra and Maas to ponder upon the possibility that a Rab23 mutation is somehow involved in the development of bifid ribs. This conception is indeed intriguing; however no known human developmental defect that is comparable to the opbmutant has been identified.

\section{Chromosomal/Gene Studies}

Scientists are divided in their opinion when it comes to the genetic nature of bifid ribs. ${ }^{[7]}$ Some argued for it

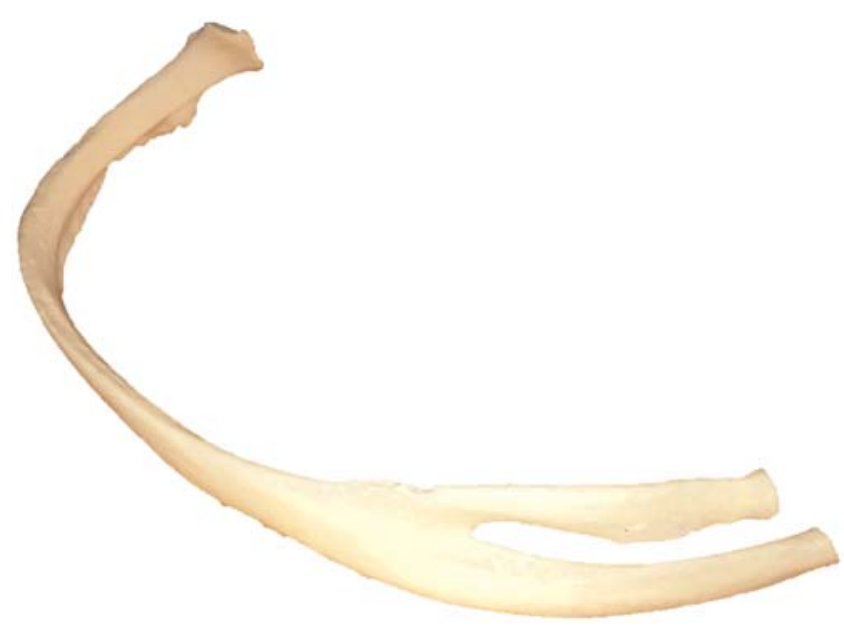

Figure 1. Isolated rib noting a bifid distal end. [Color figure can be viewed in the online issue, which is available at www.anatomy.org.tr]

being pathogenic ${ }^{[10-12]}$ while others gene-dependent. ${ }^{[7,13,14]}$ The recurring presence of bifid rib in genetic syndromes has led to the speculation that bifid rib is a gene-controlled pathological malformation. ${ }^{[7]}$ On the other hand, its extremely low incidence in the general population has suggested otherwise. ${ }^{[7]}$ The congeniality of bifid ribs is also clouded with uncertainty. It has not been determined whether the development of bifid ribs is pre- or post-natal. ${ }^{[15]}$

In many occasions, a bifid rib is detected in the presence of genetic syndromes such as the nevoid basal cell carcinoma, otherwise known as Gorlin syndrome. ${ }^{[7,11,16]}$ Nevoid basal cell carcinoma syndrome (NBCCS) can be considered the most prominent genetic syndrome with which bifid ribs often co-occurs. The relationship between the rib anomaly and clinical diagnoses has yet to be determined. ${ }^{[1]}$ NBCCS is an autosomal-dominant disease with poor penetrance that is characterized by multiple basal cell carcinomas, jaw cysts, palmar/plantar pits, spinal/costal abnormalities, and primarily the calcification of the falx cerebri. ${ }^{[16]}$ In 1960, Gorlin and Goltzfirst pointed out the occurrence of bifid rib in conjunction with NBCCS and jaw cysts. While acknowledging the challenge in pinning the embryological origins of bifid rib, Gorlin and Goltz proposed the involvement of either a simple pleiotropical gene or multiple closely linked genes. ${ }^{[11]}$ Gorlin and Goltz ${ }^{[11]}$ also observed other symptoms that are potentially associated with the disease, such as skin lesions, while identifying the close relation between the three. The interchangeable use of the designations NBCCS and the newly coined "Gorlin syndrome" has been common ever since. 
Mutation in the PTCH1 gene (the human homologue of the Drosophila segment polarity gene patched) is identified in $65-80 \%$ of individuals with NBCCS. ${ }^{[16]}$ Due to challenges presented by both the mutation screening itself and its interpretation, other methods such as radiological are commonly used in complementation. ${ }^{[16]}$ Radiological evaluation is especially valuable in the early diagnosis of NBCCS in the pediatric population before the development of the disease's more prominent clinical features (i.e. jaw cysts, basal cell carcinoma, falx cerebri calcification) develop in the teenage years/early twenties. ${ }^{[16]}$ While the occurrence of bifid rib is only present in $28 \%$ of NBCCS cases, its detection is rendered a crucial part of the syndrome's early diagnosis and can possibly reduce the severity of its long-term complications. ${ }^{[17]}$

In 1963, Yunis and Gorlin ${ }^{[18]}$ took charge of the only published chromosomal study on bifid ribs in the context of NBCCS. They performed a karyotype analysis in family members of 2 unrelated individuals who are affected with Gorlin syndrome. Yunis and Gorlin detected an anomaly in chromosome number 1 in one of the affected individuals, in which an arm of one homologue was longer than the other homologue. ${ }^{[18]}$ The same anomaly was observed in another 4 (out of 11) members of this individual's family that were involved in the study, yet unaffected by the syndrome.$^{[18]}$ No chromosome abnormality was observed in any member of the second family, affected or unaffected.$^{[18]}$ In conclusion of their study, Yunis and Gorlin ${ }^{[18]}$ attributed the longer arm of the homologue to a partial trisomy with no harmful effect. They ruled the chromosome abnormality as irrelevant to Gorlin syndrome. ${ }^{[18]}$ While this result is not all too surprising, it is important to keep in mind that the study involved no more than two families. And as the case with all that may appear as trends on such a rare anomaly, careful considerations need to be taken prior to drawing any conclusion. Regardless, it will still be interesting to see the results of a chromosomal study directed more towards bifid rib itself rather than Gorlin syndromeespecially recalling the aforementioned fact that bifid rib is only observed in approximately $28 \%$ of reported cases on Gorlin syndrome. ${ }^{[1]}$

In favor of the gene-dependent hypothesis, two studies that were done in 1995 reported a possible correlation between a couple mice genes, Hoxc-9 and Mrf4, and the bifurcation at the distal parts of the ribs. ${ }^{[1,14]}$ The question on whether or not a comparable trend persists in humans has not been investigated. Also supporting this side of the argument, Edgar J. Martin noticed that the incidence of bifid ribs is significantly higher among Samoans in contrast with other populations. ${ }^{[15]}$ In 1960 , Martin conducted a research in an attempt to shed light on the matter. Samoans are categorized as the native inhabitants of Samoa, an isolated group of islands in the South Pacific. ${ }^{[15]}$ The population consists of a self-contained ethnic unit of Polynesian ethnicity, numbering about 115,000 around the time of study. ${ }^{[15]}$ From close examination of the subjects' chest radiography, Martin and his colleagues have found that up to $8.4 \%$ Samoan adults were affected by rib abnormalities, though a correlation with other disorder(s) was not identified. ${ }^{[15,19]}$ By the end of his study, the general factors that might be involved in the development of bifid ribs in general and its high incidence among Samoans remain elusive to Martin. Shifting focus away from the Samoans and back to the general population, Osawa et al. ${ }^{[7]}$ thought that it is highly unlikely for the anomaly to be gene-controlled. After all, it only affects barely $1 \%$ of most populations. ${ }^{[7]}$ Altogether, this argument seems to have the more acceptable stance that suits the minimal understanding on the nature of bifid ribs.

\section{Symptoms, Complications and Case Studies}

There have been a decent number of case reports written worldwide on the diagnoses of bifid ribs, whether as an isolated symptom or in association with other malformations. This section aims to explore and summarize such reports:

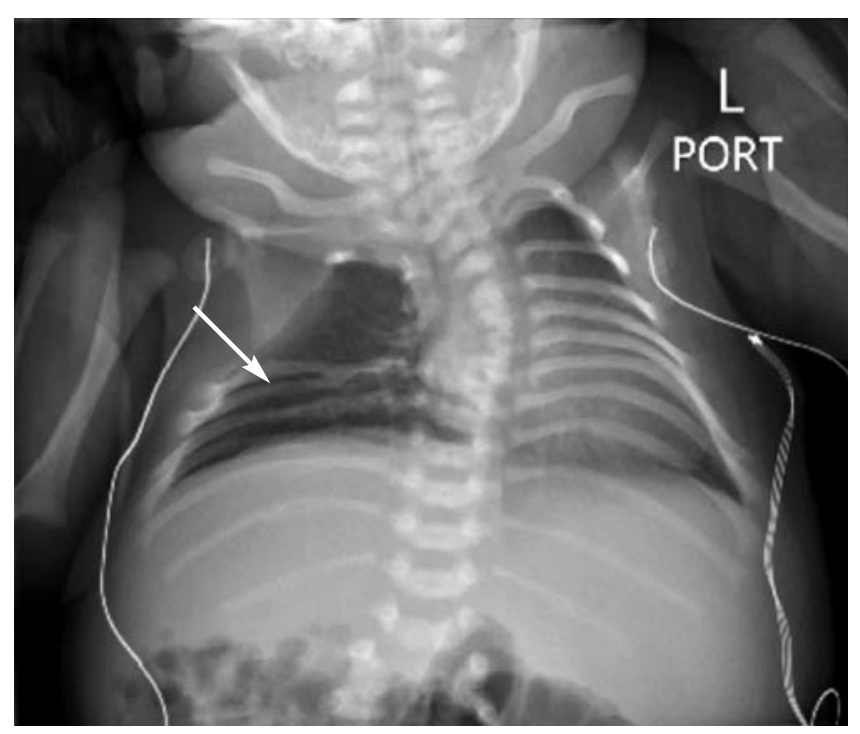

Figure 2. AP chest radiograph of an infant noted to have missing ribs and a bifurcated rib (arrow). 
An emphasis will be laid on observations that were obtained from chest radiography (i.e. $\mathrm{x}$-ray/ roentgenogram) (Figures 2 and 3), mainly during routine check-ups and general physical evaluations. MRI and CT scan (Figure 4) are often utilized to follow up the initial detection of an anomaly. ${ }^{[20]}$ These supplementary methods have been proven helpful in pinpointing more specific symptoms. ${ }^{[20-22]}$

While bifid rib is generally described as asymptomatic, a number of literatures have noted symptoms that were experienced by patients diagnosed with the condition: respiratory difficulty, neurological complaints, chest deformity, chest pain, dyspnea, and hemoptysis. ${ }^{[6,23]}$ The diagnosis of bifid rib is considered very challenging especially in children with multiple other anomalies, and is therefore often overlooked. ${ }^{[1]}$

Radiographic examination of the ribs can yield noteworthy diagnostic clues that point to other diseases. ${ }^{[20]}$ The diseases that have been reported include, but are not limited to: congenital bone dysplasia, acquired metabolic diseases, iatrogenic conditions, neoplasms, vertebral segmentation, spondylocostaland spondylothoracicdysostosis, and thoracic outlet syndrome. ${ }^{[1,20]}$ Other studies have identified additional diseases/malformations that can be associated with bifid rib specifically: deficient lateral clavicle, mandibular hypoplasia, macrocephaly, mental retardation, chest wall tumor, and costal fracture. ${ }^{[4,24]}$ Unlike other rib anomalies, bifid rib usually occurs in the absence of vertebral defects. ${ }^{[1]}$

Considering mesodermal origins of the ribs, it is sensible that costal abnormalities are often associated with defects in organs of mesodermal origin such as the heart and kidney ${ }^{[1]}$ Cardiac, renal, and urogenital defects are among the most prevalent symptoms associated with rib abnormalities, whether as part of genetic syndromes or isolated congenital malformations. ${ }^{[1,20]}$ Yet, associated abnormalities in endo- and ectoderm derived structures is also existent. Martinez-Frias et al. ${ }^{[2]}$ suggested that such phenomenon arises from the disturbance of what was introduced as developmental field, a part of an embryo that coordinately produces identical reaction(s) to various dysmorphogenetic courses. They proposed that its disturbance leads to multiple anomalies that are mostly contiguous, but sometimes distantly located. ${ }^{[25]}$

Several case reports featured the detection of bifid rib in deceased individuals. Most of these observations were made following a cadaveric dissection; yet in one particular case, multiple rib bifurcations were detected in a preserved anatomical specimen. ${ }^{[8]}$ Upon detecting bifid rib(s) during a cadaveric dissection, researchers often

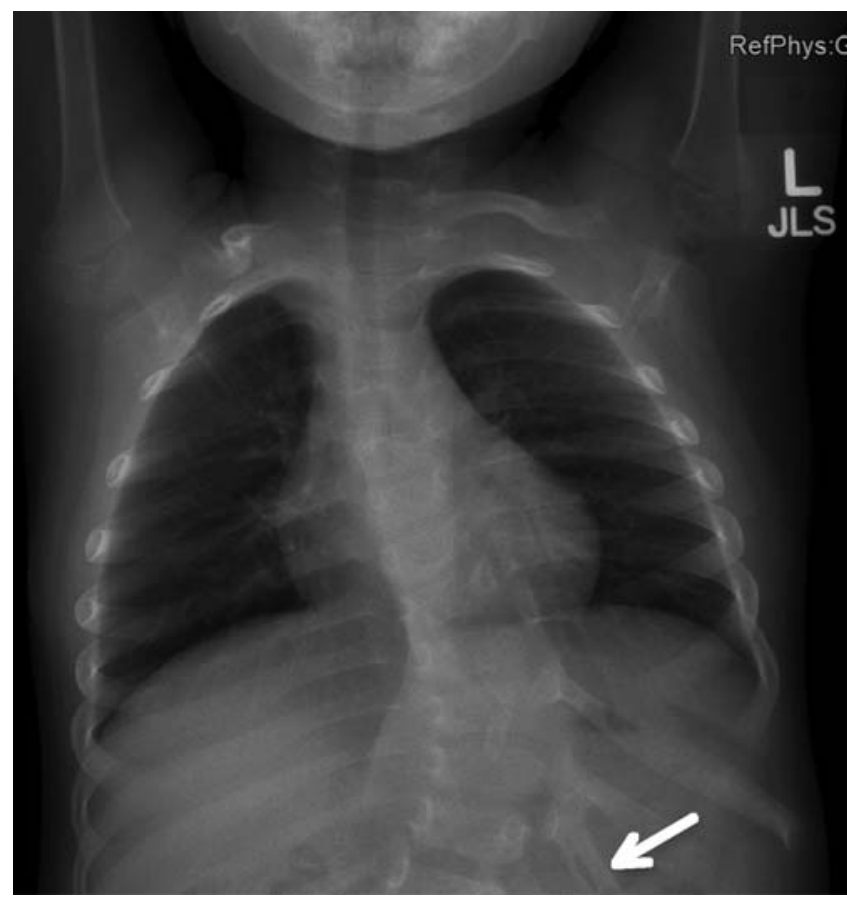

Figure 3. AP chest radiograph of a child noting an incidental bifid rib (arrow).

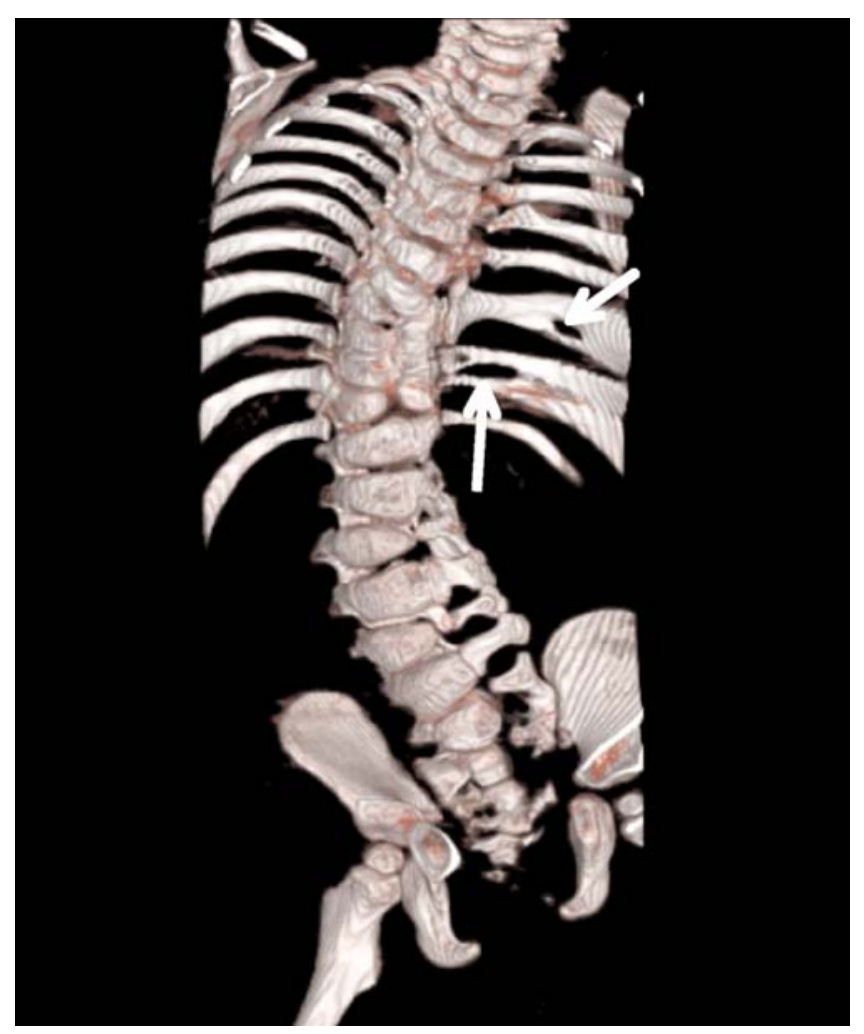

Figure 4. 3D CT reconstruction of a patient with multiple spine anomalies and also found to have bifid ribs (arrows). [Color figure can be viewed in the online issue, which is available at www.anatomy.org.tr] 
noted additional features that could point to NBCCS. However, this does not necessarily mean that the respective individuals were ever diagnosed with the syndrome while living.

\section{Association with Gorlin Syndrome}

In 2013, Stickley et al. ${ }^{[17]}$ discovered bifurcation of the right 4th rib in an 85-year-old female cadaver whose cause of death was identified as brain tumor. The costochondral joints were reportedly present on both superior and inferior portions of the bifid rib. No intercostal muscles or vessels were found within bifurcation. Rather, a single layer of fascia was present - superficial to the rib. A single vein was noted along the posterior inferior portion of the fascia. A narrowed intercostal space in the region of bifurcation was reported in comparison with the left, non-bifurcated ribs.

Song et al. ${ }^{[4]}$ report was based on the evaluation of three male cadavers $(80,59$, and 50-years-old at death). A single bifurcation on the right 4th rib was detected in all three cases. No irregular observation was made regarding the vessel and nerve distribution in the bifid intercostal space(s) in all three cases. As discussed earlier, the bifid intercostal space was filled with intercostal muscles and supplied by the third anterior intercostal artery from the internal thoracic artery. The 4th intercostal nerve ran along the inferior margin of the bifid rib and innervated the intercostal muscles occupying the bifid space. However, in one case, a branch from the 3 rd intercostal nerve supplied the bifid spacein addition to the 4th intercostal nerve.

Osawa et al. ${ }^{[7]}$ reported two cases of bifid ribs in two adult Japanese male cadavers. The first case was involved a bifid right $3 \mathrm{rd}$ rib. The other revealed a rare case of bilateral bifid ribs of the right $3 \mathrm{rd}$ and left 4th ribs. There were no findings indicative of Gorlin syndrome.

Oostra and Maas ${ }^{[8]}$ reported on the skeleton of a newborn infant found to have bifurcation of the left 2 nd to 5 th ribs and the right 7 th rib. Oostra and Maas considered the possibility of Gorlin syndrome for this case. ${ }^{[8]}$

\section{Association with Oral Anomalies and Occasional Skin Lesions}

In 1964, Meerkoter and Sheer ${ }^{[26]}$ reported a case on a 19year-old female Caucasian patient admitted to the Oral and Dental Hospital of the University of Witwatersrand in Johannesburg, South Africa. The patient initially came in to have her unerupted 3rd molars examined. Her physical evaluation noted the following additional obser- vations: thoracic and lumbar skin lesions, and congenital cataracts. Her chest film revealed bifurcation on the left 3rd, 4th and 8th ribs, and the right 4th rib.

In 1951, Binkley and Johnson ${ }^{[27]}$ reported a case on a 30-year-old female Caucasian with multiple dental follicular cysts in both sides of the mandibles. According to the patient's account, the cysts were first detected when she was 16. The report also indicated the presence of innumerable hard papules at various parts of the body. Her chest roentgenogram revealed a bifid 6th rib.

In 1953, Gross ${ }^{[28]}$ reported a case on a 9-year-old boy with numerous papillary lesions in various areas of the body. The boy was diagnosed with epithelioma adenoids cysticum. Dental cysts were detected on the left side of mandible and maxilla. His chest roentgenogram revealed bifurcated left and right 6th ribs.

In 1960, Gorlin and Goltz ${ }^{[1]}$ reported a case on a 38year-old female who ethnically identified as Jewish. She had multiple dentigerous cysts that were first identified when she was 7 . Her chest $x$-ray revealed a bifid left 4th rib.

In 1960, Schamberg ${ }^{[2]}$ reported a case on an 18-year old Caucasian with multiple maxillary and mandibular cysts, and multiple basal cell lesions on the skin. X-ray examination revealed bifid left and right 6th ribs.

\section{Miscellaneous Extraordinary Cases}

Bifid intrathoracic rib, also known as type II intrathoracic rib, involves bifurcation in the distal portion of the normal rib. This particular anomaly, accounting for 3 out of 41 intrathoracic rib cases, is characterized by an osseous prominence of a rib into the thoracic cavity. ${ }^{[22]} \mathrm{In}$ 2006, Kamano et al. ${ }^{[2]}$ reported a case on bifid intrathoracic rib in a 21-year-old female. They proposed that the abnormality arouse from the anterior-lateral portion of the depressed left 4th rib. Another case of bifid intrathoracic rib was reported by Bottosso and Ghaye in 2008. ${ }^{[21]}$ This time, the patient was a 79-year-old male who came in for a routine check-up. The abnormality was detected on the 6th rib. In both cases, the evaluation was done by chest radiography and CT scan.

Thoracic outlet syndrome (TOS) is a quite common abnormality with broad symptomology. It is characterized as the compression of subclavian vessels and brachial plexus in the cervicoaxillary region. In 2006, Cagli et al. ${ }^{[30]}$ reported a case on a 13 -year-old girl with TOS that was caused by bifurcation of the first rib. Her chest film revealed bilateral cervical ribs that articulated with the first ribs, distally formed bifid ribs. She was successfully 
treated by surgery, excising the variant rib to decompress neural elements.

In 1999, Guttentag and Salwen ${ }^{[31]}$ presented an unusual variant of bifid rib that involved a cartilaginous duplication of a rib segment that failed to ossify.

In 1926, Bloomberg ${ }^{[32]}$ reported a case on a 4-year-old with a striking outward appearance, referred to as the "pigeon breast" appearance. His general physical evaluation noted a firm, round prominence of the chest around the level of the $3 \mathrm{rd}$ rib on the right of the sternum. The lump was approximately two and a half inches in diameter. His chest roentgenogram revealed bifid right $3 \mathrm{rd}$ and 4th ribs. While traditionally the bulging of the chest wall had been solely associated with rickets, Bloomberg attributed this observation to the crowding by the extra costal branch from the bifurcation.

In contrast to the hard lump reported in Bloomberg's cases, Batra and Lawner ${ }^{[33]}$ described a "palpable tenderness" during the physical evaluation of a 9-year-old Hispanic girl. She came to the outpatient clinic with complaints on pain in her right chest after a minor fall. Her chest radiography revealed a bifid right 5 th rib. The relevance of the pain to the abnormality was not discussed further.

\section{Conclusion}

The detection of rib anomalies, while mostly incidental, plays a substantial role in tailoring an appropriate followup radiographic and laboratory evaluation. It has been established that the specific type of rib anomaly can help identify and define associated syndromes or malformations, which will in turn provide the patient with a complete and well-rounded diagnosis. ${ }^{[1]}$ Although bifid rib neither gives rise to severe clinical afflictions nor affects a great proportion of the population, its consideration especially in perspective of associated diseases hasdemonstrated preventative advantages. Early detection and therefore, prevention, is particularly vital in the pediatric patient population as it can possibly reduce the severity of longterm complications of an associated syndrome. The recommendation to further investigate other internal malformations following the detection of rib anomalies is therefore firmly corroborated.

\section{References}

1. Wattanasirichaigoon D, Prasad C, Schneider G, Evans JA, Korf BR. Rib defects in patterns of multiple malformations: a retrospective review and phenotypic analysis of 47 cases. Am J Med Gen 2003; 122A:63-9.

2. Silverman FN, Kuhn JP, editors. Caffey's pediatric $x$-ray diagnosis: an integrated/imaging approach. 9th ed. St. Louis (MO): Mosby; 1993.
3. Rathinasabapathi MK, Perumallapalli HK. Bifid rib: a rare anomaly. Medical Journal of Dr. D.Y. Patil University 2015;8:670-1.

4. Song WC, Kim SH, Park DK, Koh KS. Bifid rib: anatomical considerations in three cases. Yonsei Med J 2009;50:300-3.

5. Etter LE. Osseous abnormalities in the thoracic cage seen in forty thousand consecutive chest photoroentgenograms. Am J Roentgenol Radium Ther 1944;51:359-63.

6. Patil VA, Lal V, Shaikh TP, Narayan P, Deolekar S. A rare case of bilateral bifid ribs: a case report. International Journal of Research in Medical Sciences 2014;2:1783-4.

7. Osawa T, Sasaki T, Matsumoto Y, Tsukamoto A, Onodera M, Nara E, Chen J-K, Fujimura A, Nozaka Y. Bifid ribs observed in the third and the fourth ribs. Kaibogaku Zasshi 1998;73:633-5.

8. Oostra RJ, Maas M. Bifid ribs and unusual vertebral anomalies diagnosed in an anatomical specimen. Am J Med Genet A 2006;140: 2135-8.

9. Spörle R, Schughart K. Paradox segmentation along inter- and intrasomitic borderlines is followed by dysmorphology of the axial skeleton in the open brain (opb) mouse mutant. Dev Genet 1998;22:35973 .

10. Schumacher R, Mai A, Gutjahr P. Association of rib anomalies and malignancy in childhood. Eur J Pediatr 1992;151:432-4.

11. Gorlin RJ, Goltz RW. Multiple nevoid basal-cell epithelioma, jaw cysts, and bifid rib: a syndrome. N Engl J Med 1960;262:908-12.

12. Koutnik AW, Kolodny SC, Hooker SP, Roche WC. Multiple nevoid basal cell epithelioma, cysts of the jaw, and bifid rib syndrome: report of a case. J Oral Surg 1975;33:686-9.

13. Suemori H, Takahashi N, Noguchi S. Hoxc-9 mutant mice show anterior transformation of the vertebrae and malformation of the sternum and ribs. Mech Dev 1995;51:265-73.

14. Zhang W, Behringer RR, Olsen EN. Inactivation of the myogenic bHLH gene MRF4 results in up-regulation of myogenin and rib anomalies. Genes Dev 1995;9:1388-99.

15. Martin EJ. Incidence of bifidity and related rib abnormalities in Samoans. Am J Phys Anthropol 1960;18:179-87.

16. Kimonis VE, Mehta SG, DiGiovanna JJ, Bale SJ, Pastakia B. Radiological features in 82 patients with nevoid basal cell carcinoma (NBCC or Gorlin) syndrome. Genet Med 2004;6:495-502.

17. Stickley CD, Tamura K, Labrash SJ, Lozanoff S. Bifurcation of the fourth rib as a possible indicator of Gorlin's syndrome in an 85-yearold female cadaver. International Journal of Anatomical Variations 2013;6:86-9.

18. Yunis JJ, Gorlin RJ. Chromosomal study in patients with cysts of the jaw, multiple nevoid basal cell carcinomata and bifid rib syndrome. Chromosoma 1963;14:146-53.

19. Rist E, Gally L, Trocme C. L'ossification des cartilages costauxdansl'especehumaine. Presse Medicale 1928;36:641-4.

20. Glass BJ, Norton KI, Mitre SA, Kang E. Pediatric ribs: a spectrum of abnormalities. Radiographics 2002;22:87-104.

21. Bottosso N, Ghaye B. Bifid intrathoracic rib. JBR-BTR 2008;91:867.

22. Kamano H, Ishihama T, Ishihama H, Kubota $Y$, Tanaka T, Satoh $\mathrm{K}$. Bifid intrathoracic rib: a case report and classification of intrathoracic ribs. Intern Med 2006;45:627-30.

23. Kupeli E, Ulubay G. Bony bridge of a bifid rib. Clev Clin J Med 2010;77:232-3. 
24. Scheepers S, Andronikou S. Beware the bifid rib. South African Journal of Radiology 2010;14:104.

25. Martinez-Frias ML, Frias JL, Opitz JM. Errors of morphogenesis and developmental field theory. Am J Med Genet 1998;76:291-6.

26. Meerkotter VA, Shear M. Multiple primordial cysts associated with bifid rib and ocular defects. Oral Surg Oral Med Oral Pathol 1964; $18: 498-503$

27. Binkley GW, Johnson HH Jr. Epithelioma adenoids cysticum: basal cell nevi. agenesis of corpus callosum and dental cysts. AMA Arch Derm Syphilol 1951;63:73-84.

28. Gross PP. Epithelioma adenoides cysticum with follicular cysts of maxilla and mandible. J Oral Surg (Chic) 1953;11:160-5.

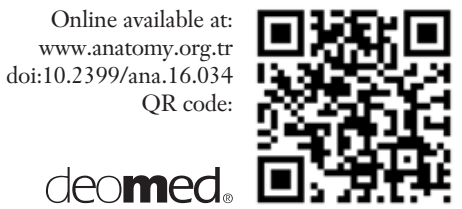

29. Schamberg IL. Basal cell nevi. Arch Dermatol 1960;81:269.

30. Cagli K, Ozcakar L, Beyazit M, Sirmali M. Thoracic outlet syndrome in an adolescent with bilateral bifid ribs. Clin Anat 2006;19: 558-60.

31. Guttentag AR, Salwen JK. Keep your eyes on the ribs: the spectrum of normal variants and diseases that involve the ribs. Radiographics 1999;19:1125-42.

32. Bloomberg MW. Bifurcate ribs - an unusual cause of deformity of the chest. Can Med Assoc J 1926;16:807-8

33. Batra D, Lawner BJ. Bifid fifth rib in a 9-year-old girl with chest pain. J Am Osteopath Assoc 2006;106:359-60.

Correspondence to: Joe Iwanaga, DDS, PhD

Seattle Science Foundation, 550 17th Ave, James Tower,

Suite 600, Seattle, WA, 98122, USA

Phone: +1 20673265 00, Fax: +1 2067326599

e-mail: joei@seattlesciencefoundation.org

Conflict of interest statement: No conflicts declared.

This is an open access article distributed under the terms of the Creative Commons Attribution-NonCommercial-NoDerivs 3.0 Unported (CC BY-NCND3.0) Licence (http://creativecommons.org/licenses/by-nc-nd/3.0/) which permits unrestricted noncommercial use, distribution, and reproduction in any medium, provided the original work is properly cited. Please cite this article as: Andrea A, Tardieu G, Fisahn C, Iwanaga J, Oskouian RJ, Tubbs RS. Bifid ribs: a comprehensive review. Anatomy 2016;10(3):221-227. 